\title{
MicroRNA-145 inhibits proliferation and induces apoptosis in human prostate carcinoma by upregulating long non-coding RNA GAS5
}

\author{
XIN XIE, JUN DAI, XIN HUANG, CHEN FANG and WEI HE \\ Department of Urology, Ruijin Hospital, Shanghai Jiaotong University \\ School of Medicine, Shanghai 200025, P.R. China
}

Received October 26, 2018; Accepted March 29, 2019

DOI: $10.3892 / \mathrm{ol} .2019 .10419$

\begin{abstract}
MicroRNA-145 (miR-145) and long non-coding RNA (lncRNA) growth arrest specific 5 (GAS5) function as tumor suppressors in prostate carcinoma. The aim of the present study was to investigate the role of miR-145 and IncRNA GAS5 in prostate carcinoma. In the present study, miR-145 and lncRNA GAS5 expression levels were demonstrated to be downregulated in tumor tissues compared with adjacent healthy tissues of patients with prostate carcinoma. miR-145 and lncRNA GAS5 expression levels were found to be positively and significantly correlated in tumor tissues, but not in adjacent healthy tissues. A follow-up study revealed that low miR-145 and lncRNA GAS5 expression levels were associated with poor survival. Overexpression of miR-145 resulted in upregulated IncRNA GAS5, whereas 1ncRNA GAS5 overexpression or silencing did not affect miR-145 expression. Overexpression of miR-145 and lncRNA GAS5 promoted apoptosis and inhibited cell proliferation in prostate carcinoma cell lines, whereas lncRNA GAS5 knockdown had an opposite effect. In addition, lncRNA GAS5 knockdown partially attenuated the effect of miR-145 overexpression of cancer cell proliferation and apoptosis. Therefore, miR-145 may inhibit cell proliferation and induce apoptosis in human prostate carcinoma by upregulating lncRNA GAS5.
\end{abstract}

\section{Introduction}

Prostate carcinoma is one of the most frequently diagnosed malignancies in men worldwide (1). As a heavy burden on public health, prostate carcinoma has an unacceptably high mortality rate (2). Patients with prostate carcinoma are mostly

Correspondence to: Dr Wei He, Department of Urology, Ruijin Hospital, Shanghai Jiaotong University School of Medicine, 197 Ruijin 2nd Road, Shanghai 200025, P.R. China

E-mail:mc13025@163.com

Key words: prostate carcinoma, microRNA-145, long non-coding RNA growth arrest specific 5, proliferation, apoptosis treated with androgen ablation therapies; although there is a high rate of initial response, emergence of castration-resistant prostate carcinoma in $10-20 \%$ of patients, results in failure of treatment (3). Prostate cancer affects 1 in 9 men during their lifetime and $<30 \%$ of patients with prostate cancer with evidence of metastasis will live longer than 5 years in cases $(2,3)$. In addition, early stages of prostate carcinoma lack do not exhibit any noticeable symptoms and the majority of present are diagnosed with tumor metastasis, which makes surgical intervention, a radical treatment for solid tumors, unsuitable $(4,5)$.

Non-coding RNAs (ncRNAs) are involved in many physiological and pathological processes $(6,7)$. ncRNAs are divided into subgroups based on their length and functions; long ncRNAs (lncRNAs) are ncRNAs $>200$ nucleotides (8). A growing body of literature has shown that lncRNAs participate in cancer biology through their interactions with multiple signaling molecules (8-10), including microRNAs (miRNAs), which is another subgroup of ncRNAs (11). miR-145 and lncRNA growth arrest specific 5 (GAS5) serve a role as tumor suppressor in prostate carcinoma $(12,13)$. Mir-145 and GAS5 negatively regulate cancer progression and are downregulated in prostate carcinoma $(12,13)$. The results of the present study provided further evidence that miR-145 and lncRNA GAS5 may function in prostate carcinoma and demonstrated that miR-145 may inhibit cell proliferation and induce apoptosis in human prostate carcinoma possibly by upregulating lncRNA GAS5.

\section{Materials and methods}

Tissue samples and cell culture. Tumor tissue and adjacent healthy tissue samples were collected from 62 patients with prostate carcinoma who were admitted to Ruijin Hospital, Shanghai Jiaotong University (Shanghai, China) between January 2010 and January 2013. Patients were aged between 38 and 70 years (mean, 51.2 \pm 5.3 years). Inclusion criteria: i) Patients diagnosed by pathological examinations in Ruijin Hospital, Shanghai Jiaotong University; ii) patients with complete medical records treated at Ruijin Hospital, Shanghai Jiaotong University; iii) patients who participated in the 5-year follow-up after discharge; iv) patients willing to participate. 
Exclusion criteria: i) Patients diagnosed with other diseases; ii) patients who were transferred to other hospitals during treatment; iii) patients who died from other causes during the follow-up period. There were 12 cases in stage I, 14 cases in stage II, 18 cases in stage III and 18 cases in stage IV. The study was approved by the Ethics Committee of Ruijin Hospital, Shanghai Jiaotong University. All participants signed informed consent before admission.

The 22Rv1 human prostate carcinoma cell line was used in this study. Cells were obtained from American Type Culture Collection (ATCC; Manassas, VA, USA) and cultured in DMEM containing 10\% fetal bovine serum (cat. no. 30-2020; ATCC) at $37^{\circ} \mathrm{C}$ in a $5 \% \mathrm{CO}_{2}$ incubator with $98 \%$ humidity.

Follow-up study. Following discharge, all patients were followed-up monthly for 5 years and overall survival was recorded. Three patients who died from other causes were not included; a total of 57 patients completed the follow-up.

Reverse transcription-quantitative PCR (RT-qPCR). To detect the expression levels of miR-145, miRNAs were extracted from $0.1 \mathrm{~g}$ of tissue specimen from each sample and $1 \times 10^{5}$ cells using miRNeasy Mini kit (Qiagen, Inc., Valencia, CA, USA), and PCR reaction systems were prepared using TaqMan MicroRNA Reverse Transcription kit (Thermo Fisher Scientific, Inc., Waltham, MA, USA). To detect the expression levels of IncRNA GAS5, total RNAs were extracted from $0.1 \mathrm{~g}$ of tissue specimen from each sample and $1 \times 10^{5}$ cells using TRIzol reagent (Invitrogen; Thermo Fisher Scientific, Inc.), reverse transcription was performed using MMLV Reverse Transcriptase 1st-Strand cDNA Synthesis kit (Lucigen Corporation, Middleton, WI, USA), and SYBR ${ }^{\circledR}$ Green Real-Time PCR Master Mix (Thermo Fisher Scientific, Inc.) was used to prepare qPCR reaction systems. The thermocycling conditions were $95^{\circ} \mathrm{C}$ for $55 \mathrm{sec}$, followed by 40 cycles of $95^{\circ} \mathrm{C}$ for $25 \mathrm{sec}$ and $55.5^{\circ} \mathrm{C}$ for $30 \mathrm{sec}$. Primers for miR-145, lncRNA GAS5 and endogenous controls U6 and $\beta$-actin were designed and synthesized by Sangon Biotech Co., Ltd. (Shanghai, China). Primer sequences were: miR-145 forward, 5'-CAGTGCGTGTCGTGGAGT-3' and reverse, 5'-AGGTCCAGTTTTCCCAGG-3'; U6 forward, 5'-CGCTTC ACGAATTTGCGTGTCA-3' and reverse, 5'-GCTTCGGCA GCACATATACTAAAAT-3'; GAS5 forward, 5'-CACACA GGCATTAGACAGA-3' and reverse, 5'-GCTCCACACAGT GTAGTCA-3'; $\beta$-actin forward, 5'-GACCTCTATGCCAAC ACAG-3' and reverse, 5'-AGTACTTGCGCTCAGGAGGA-3'. Expression of miR-145 was normalized to U6 and expression of lncRNA GAS5 was normalized to $\beta$-actin using the $2^{-\Delta \Delta C q}$ method (14).

Cell transfection. IncRNA GAS5 pcDNA3.1 expression vector and siRNA (5'-GCAGAACCATAAAGATGGTCCA-3') were designed and constructed by Sangon Biotech Co., Ltd. Empty vectors and negative control (NC) siRNA (5'-TTCTCCGAA CGTGTCACGTTT-3') were also provided by Sangon Biotech Co., Ltd. MISSION ${ }^{\circledR}$ microRNA mimic hsa-miR-145 and scrambled NC miRNAs were obtained from Sigma-Aldrich (Merck KGaA, Darmstadt, Germany). Cell transfections were performed using Lipofectamine ${ }^{\circledR} 2000$ reagent (Thermo Fisher Scientific, Inc.) at $37^{\circ} \mathrm{C}$ with vectors, siRNAs and
miRNAs at doses of 10,40 and $40 \mathrm{nM}$, respectively. Cells were incubated with the transfection mixtures for $6 \mathrm{~h}$. Cells treated with Lipofectamine ${ }^{\circledR} 2000$ reagent only were used as untreated control cells. Cells transfected with empty vectors, NC siRNAs, or scrambled NC miRNAs were used as transfection controls. The thresholds for successful transfections were $200 \%$ for IncRNA GAS5 and miR-145 overexpression and $50 \%$ for lncRNA GAS5 knockdown. Further experiments were performed $24 \mathrm{~h}$ post-transfection.

Cell Counting Kit-8 (CCK-8) assay. Cell proliferation was detected using CCK-8 assay (Dojindo Molecular Technologies, Inc., Kumamoto, Japan). Cell suspensions $\left(5 \times 10^{4}\right.$ cells $\left./ \mathrm{ml}\right)$ were cultivated in a 96 -well plate $(0.1 \mathrm{ml} /$ well $)$ under normal conditions $\left(37^{\circ} \mathrm{C} ; 5 \% \mathrm{CO}_{2}\right)$, and $15 \mu \mathrm{lCCK}-8$ solution (Dojindo Molecular Technologies, Inc.) was added into each well at 24, 48, 72 and 96 h. Cells were incubated with CCK-8 solution for $4 \mathrm{~h}$. Optical density values at $450 \mathrm{~nm}$ were measured using a plate reader to determine cell proliferation rate.

Apoptosis assay. Apoptosis was detected using cell a apoptosis assay. Serum-free DMEM was used to prepare cell suspensions $\left(5 \times 10^{4}\right.$ cells $\left./ \mathrm{ml}\right)$. Cells were transferred to a 6 -well plate $(10 \mathrm{ml} /$ well $)$, cultivated for $60 \mathrm{~h}$, and cell digestion with $0.25 \%$ trypsin was performed. Annexin V-FITC (Dojindo, Kumamoto, Japan) and propidium iodide (PI) staining was performed at room temperature for $30 \mathrm{~min}$ in the dark, and then flow cytometry was performed using BD Biosciences 2 Laser 4 Color FacsCalibur Flow Cytometer (BD Biosciences, Franklin Lakes, NJ, USA) to detect apoptotic cells. Data were analyzed using BD Paint-A-Gate ${ }^{\mathrm{TM}}$ Pro Software (BD Biosciences).

Statistical analysis. All experiments were performed in triplicate and data are presented as the mean \pm standard deviation. Comparisons of IncRNA GAS5 and miR-145 expression between tumors and adjacent healthy tissues were performed using Student's paired t-test. Comparisons among multiple groups were performed by one-way analysis of variance followed by Fisher's Least Significant Difference post hoc test. Correlation analyses between the expression levels of lncRNA GAS5 and miR-145 were performed using Pearson's correlation coefficient. Patients were divided into high $(n=32)$ and low $(n=30)$ lncRNA GAS5 expression groups, as well as high $(n=28)$ and low $(n=34)$ miR-145 expression groups according to Youden's index. Association analyses between GAS5 and miR-145 expression in tumor tissue and patients' clinicopathological data were performed by $\chi^{2}$ test. Kaplan-Meier method was used to plot survival curves, which were compared using logrank test. $\mathrm{P}<0.05$ was considered to indicate a statistically significant difference.

\section{Results}

lncRNA GAS5 and miR-145 expression levels are downregulated in tumor tissues compared with adjacent healthy tissues in patients with prostate carcinoma. Expression levels of lncRNA GAS5 and miR-145 in 62 tumor tissues and adjacent healthy tissues were detected by RT-qPCR. Compared with adjacent healthy tissues, expression of lncRNA GAS5 (Fig. 1A) 

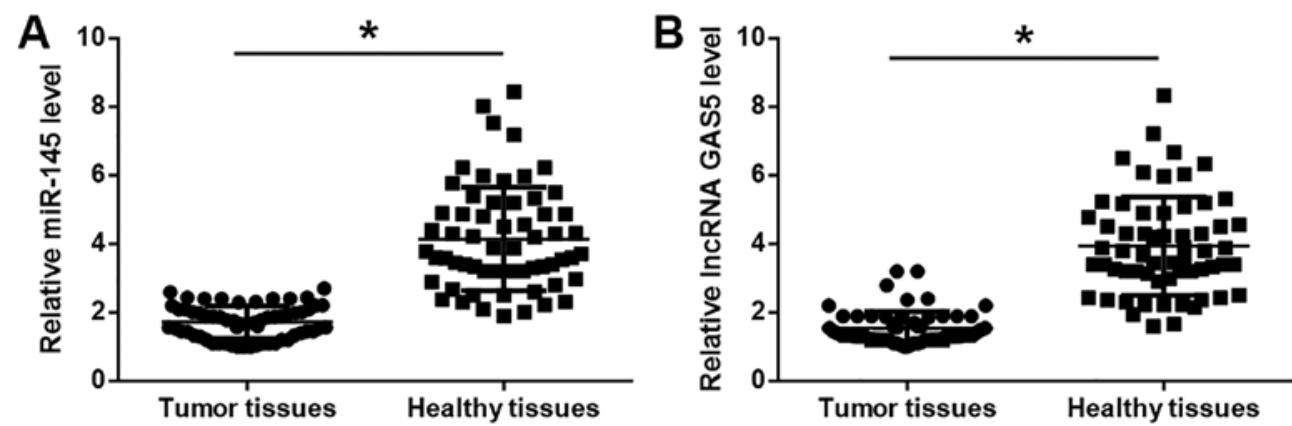

Figure 1. Expression levels of lncRNA GAS5 and miR-145 are downregulated in tumor tissues compared with adjacent healthy tissues of patients with prostate carcinoma. (A and B) Compared with adjacent healthy tissues, expression of (A) lncRNA GAS5 and (B) miR-145 were significantly downregulated in tumor tissues. ${ }^{\mathrm{P}}<0.05$. lncRNA GAS5, long non-coding RNA growth arrest specific 5; miR-145, microRNA-145.
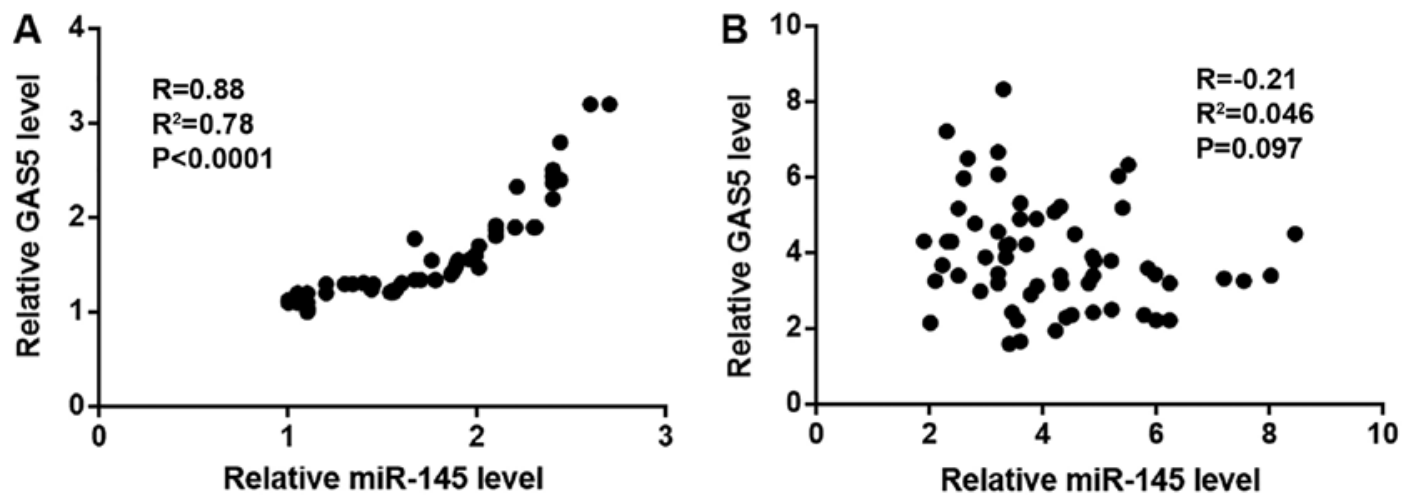

Figure 2. Expression levels of miR-145 and lncRNA GAS5 are correlated in tumor tissues. (A and B) Expression levels of miR-145 and lncRNA GAS5 were positively and significantly correlated in (A) tumor tissues, but not in (B) adjacent healthy tissues. IncRNA GAS5, long non-coding RNA growth arrest specific 5; miR-145, microRNA-145.
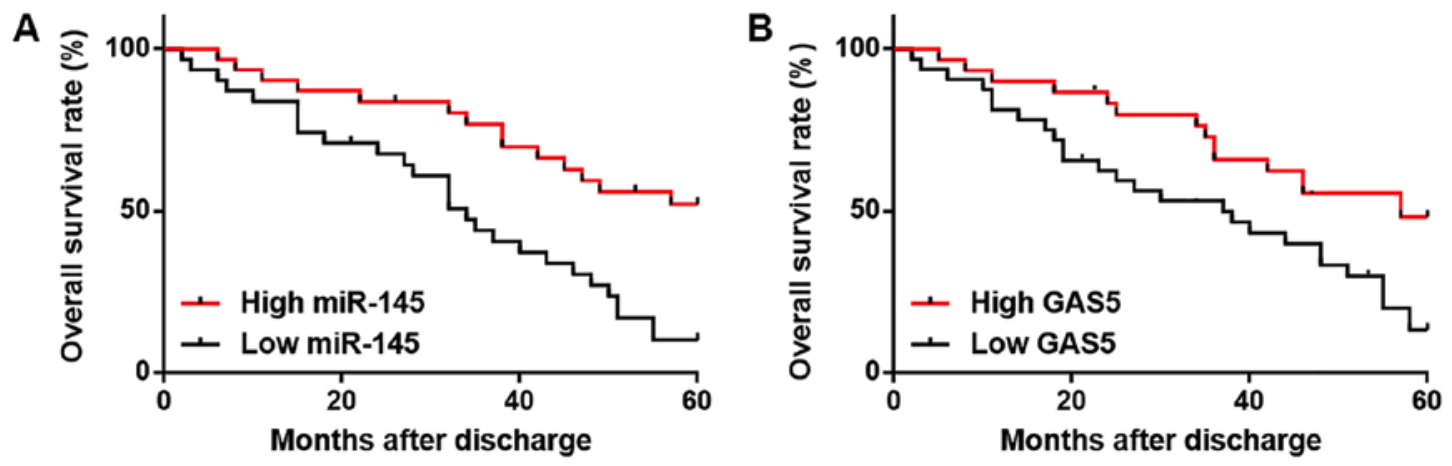

Figure 3. Low expression levels of miR-145 and lncRNA GAS5 are associated with poor survival. (A and B) Patients with low expression levels of (A) miR-145 and (B) lncRNA GAS5 exhibited lower survival rates compared with patients with high miR-145 and lncRNA GAS5 expression levels, respectively. lncRNA GAS5, long non-coding RNA growth arrest specific 5; miR-145, microRNA-145.

and miR-145 (Fig. 1B) were significantly downregulated in tumor tissues $(\mathrm{P}<0.05)$.

IncRNA GAS5 and miR-145 expression levels are positively correlated in tumor tissues. Correlation between the expression levels of lncRNA GAS5 and miR-145 was detected using Pearson's correlation coefficient. Expression levels of miR-145 and IncRNA GAS5 were positively and significantly correlated in tumor tissues (Fig. 2A). By contrast, no relationship was observed between lncRNA GAS5 and miR-145 expression levels in adjacent tissues (Fig. 2B).
Low miR-145 and lncRNA GAS5 expression levels are associated with poor survival. Patients were divided into high $(\mathrm{n}=32)$ and low $(\mathrm{n}=30)$ lncRNA GAS5 (cutoff value $=1.58)$, as well as high $(n=28)$ and low $(n=34)$ miR-145 (cutoff value=1.64) expression groups according Youden's index. $\chi^{2}$ test revealed no significant association between expression levels of lncRNA GAS5 (Table I) and miR-145 (Table II) in tumor tissues and patient age or clinical stage. Kaplan-Meier method was used to plot survival curves, which were compared using logrank test. Patients in the low miR-145 (Fig. 3A) and low lncRNA GAS5 (Fig. 3B) groups exhibited significantly lower overall survival 
Table I. Association between lncRNA GAS5 expression levels in tumor tissue and patient clinicopathological characteristics.

\begin{tabular}{|c|c|c|c|c|c|}
\hline \multirow[b]{2}{*}{ Clinicopathological factor } & \multirow[b]{2}{*}{ Cases $(n=62)$} & \multicolumn{2}{|c|}{ Expression } & \multirow[b]{2}{*}{$\chi^{2}$} & \multirow[b]{2}{*}{ P-value } \\
\hline & & High & Low & & \\
\hline Age (years) & & & & 0.59 & 0.44 \\
\hline$>50$ & 30 & 17 & 13 & & \\
\hline$\leq 50$ & 32 & 15 & 17 & & \\
\hline Stage & & & & 0.78 & 0.85 \\
\hline I & 12 & 7 & 5 & & \\
\hline II & 14 & 8 & 6 & & \\
\hline III & 18 & 8 & 10 & & \\
\hline IV & 18 & 9 & 9 & & \\
\hline
\end{tabular}

lncRNA GAS5, long non-coding RNA growth arrest specific 5.

Table II. Association between miR-145 expression levels in tumor tissue and patient clinicopathological data.

\begin{tabular}{|c|c|c|c|c|c|}
\hline \multirow[b]{2}{*}{ Clinicopathological factor } & \multirow[b]{2}{*}{ Cases $(n=62)$} & \multicolumn{2}{|c|}{ Expression } & \multirow[b]{2}{*}{$\chi^{2}$} & \multirow[b]{2}{*}{ P-value } \\
\hline & & High & Low & & \\
\hline Age (years) & & & & 1.56 & 0.21 \\
\hline$>50$ & 30 & 16 & 14 & & \\
\hline$\leq 50$ & 32 & 12 & 20 & & \\
\hline Stage & & & & 1.16 & 0.76 \\
\hline I & 12 & 5 & 7 & & \\
\hline II & 14 & 6 & 8 & & \\
\hline III & 18 & 10 & 8 & & \\
\hline IV & 18 & 7 & 11 & & \\
\hline
\end{tabular}

miR-145, microRNA-145.

rates compared with patients in the high miR-145 and high lncRNA GAS5 groups $(\mathrm{P}=0.021)$.

Overexpression of miR-145 results in upregulated lncRNA GAS5. The significant and positive correlation between miR-145 and IncRNA GAS5 indicated a possible interaction between them. Overexpression experiments were performed in 22Rv1 prostate cancer cells to further investigate the interactions between miR-145 and lncRNA GAS5. Compared with control and NC groups, overexpression of miR-145 led to upregulated lncRNA GAS5 ( $\mathrm{P}<0.05$; Fig. 4A). By contrast, lncRNA GAS5 overexpression ( $\mathrm{P}>0.05$; Fig. 4B) and siRNA silencing ( $\mathrm{P}>0.05$; Fig. 4C) caused no significant changes in expression levels of miR-145.

Overexpression of $\mathrm{miR}-145$ inhibits cell proliferation and promotes apoptosis through lncRNA GAS5. Compared with control and NC groups, overexpression of miR-145 and lncRNA GAS5 led to significantly inhibited proliferation (Fig. 5A) and increased apoptosis (Fig. 5B) of 22Rv1 prostate cancer cells $(\mathrm{P}<0.05)$. lncRNA GAS5 knockdown attenuated the effects of miR-145 overexpression of cell proliferation (Fig. 5A) and apoptosis (Fig. 5B and C) $(\mathrm{P}<0.05)$.

\section{Discussion}

miR-145 and lncRNA GAS5 have exhibit similar functions in regulating the behaviours of cancerous cells during the development of prostate carcinoma $(12,13)$; however, no studies examining a potential interaction have been published, to the best of our knowledge. The present study provided further evidence to support the role of miR-145 and lncRNA GAS5 as tumor suppressors in prostate carcinoma. The results also revealed that miR-145 inhibited cell proliferation and induced apoptosis in human prostate carcinoma possibly by upregulating lncRNA GAS5.

The interaction between IncRNAs and miRNAs are frequently reported in the development of human cancers. For example, during the development of hepatocellular cancer, miR-29a inhibits lncRNA maternally expressed 3 expression through promoter hypermethylation (15); miRNA-218-5p is negatively regulated by 1 cRNA colon cancer-associated transcript 1 to promote gallbladder cancer development (16). The present study focused on miR-145 and lncRNA GAS5 since they have similar functions in inhibiting prostate carcinoma $(12,13)$. The results indicated that miR-145 may 

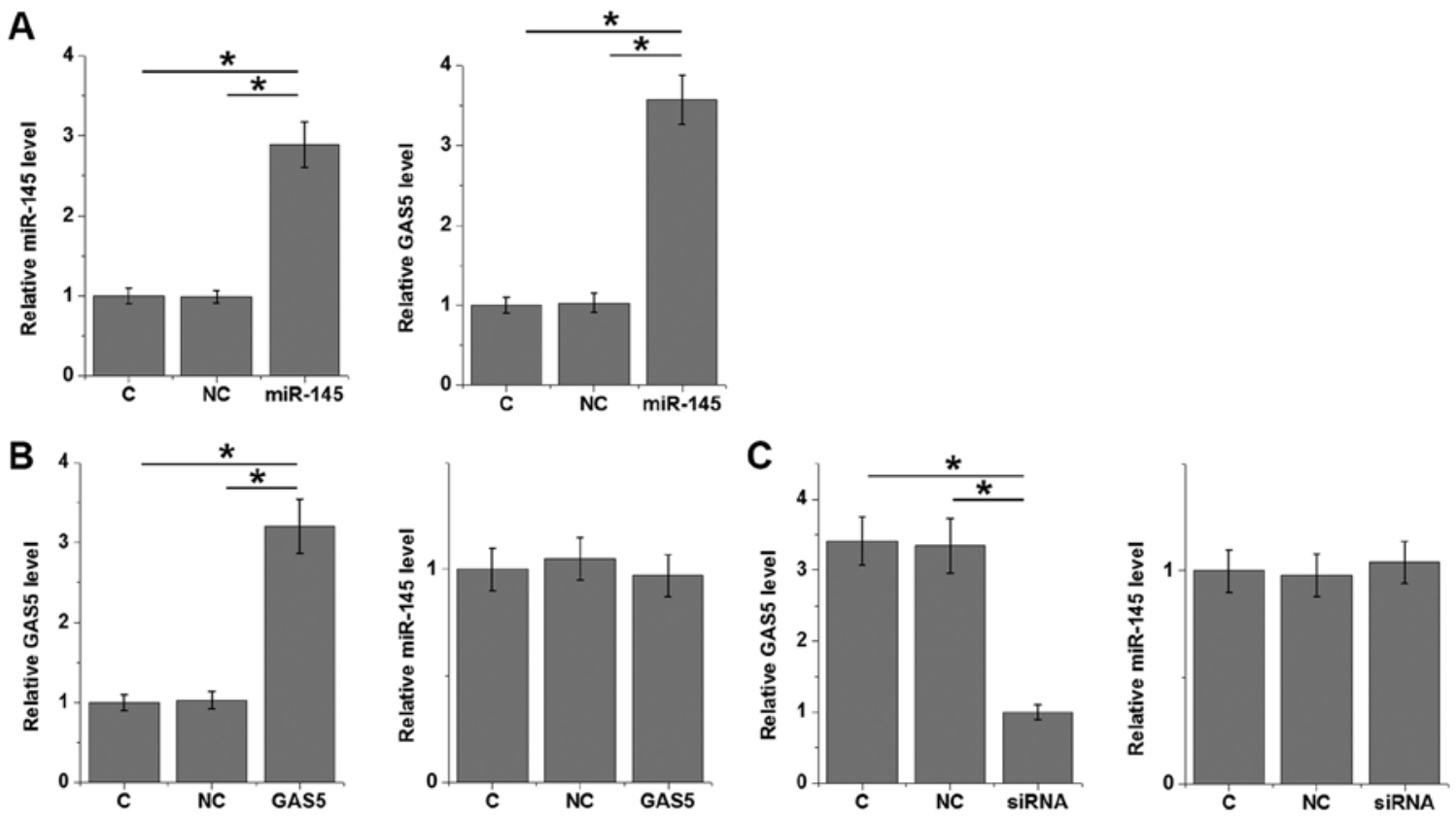

Figure 4. Overexpression of miR-145 results in upregulated lncRNA GAS5. (A) Overexpression of miR-145 led to upregulated lncRNA GAS5 in 22Rv1 prostate cancer cells. (B) lncRNA GAS5 overexpression and (C) siRNA silencing induced no significant changes in expression levels of miR-145. "P<0.05. C, untransfected control; lncRNA GAS5, long non-coding RNA growth arrest specific 5; miR-145, microRNA-145; NC, negative control.
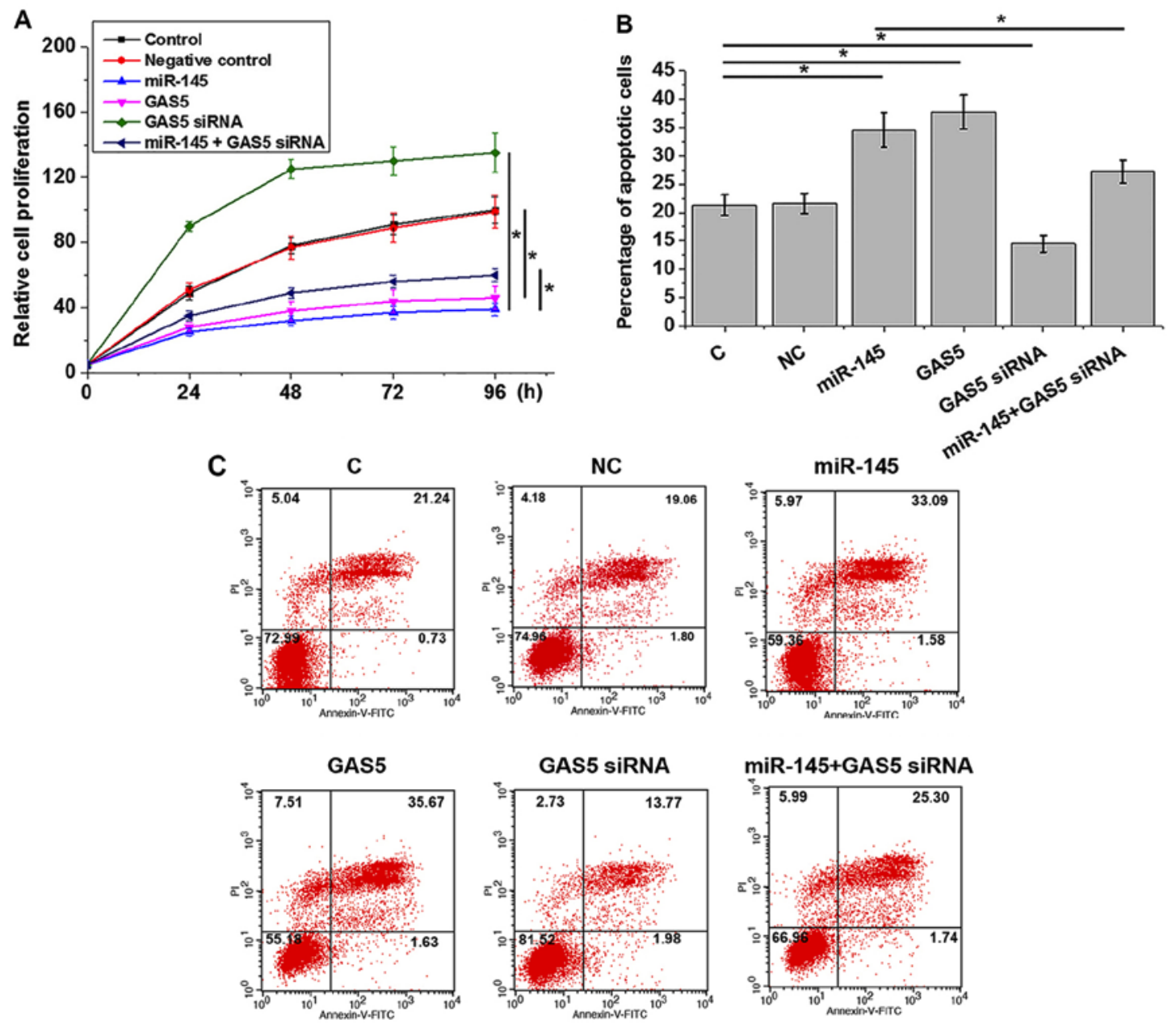

Figure 5. Overexpression of miR-145 inhibits cell proliferation and promotes cell apoptosis through lncRNA GAS5. (A and B) Overexpression of miR-145 and lncRNA GAS5 led to (A) significantly inhibited proliferation and (B) increased apoptosis of 22Rv1 prostate cancer cells. IncRNA GAS5 knockdown attenuated the effects of miR-145 overexpression on (A) cell proliferation and (B) apoptosis. (C) Representative images of apoptosis assay results. "P<0.05. C, untransfected control; lncRNA GAS5, long non-coding RNA growth arrest specific 5; miR-145, microRNA-145; NC, negative control. 
indirectly upregulate lncRNA GAS5 in prostate carcinoma cells. In a recent study, Xue et al demonstrated that lncRNA GAS5 targets miR-103 through the AKT serine/threonine kinase/mammalian target of rapamycin pathway to inhibit the progression of prostate carcinoma (17). Therefore, miRNAs may be upstream and downstream of 1ncRNA GAS5 to participate in the development of prostate carcinoma.

The present study failed to elucidate the molecular mechanism of the regulation of lncRNA GAS5 by miR-145 in prostate carcinoma cells. It has been reported that Notch-1 negatively regulates lncRNA GAS5 to promote breast cancer cell proliferation (18). In addition, miRNA-145 targets Notch signaling to induce apoptosis in glioma cells (19). However, no significant changes in expression levels of Notch-1 are observed after miRNA-145 overexpression (data not shown), which suggests that Notch-1 is unlikely the mediator between miRNA-145 and lncRNA GAS5 in prostate carcinoma. Notably, the present study demonstrated that expression levels of miR-145 and lncRNA GAS5 were positively and significantly correlated in tumor tissues, but not in adjacent healthy tissues. It is hypothesized that one of the existing prostate carcinoma-related factors may mediate the interactions between IncRNA GAS5 and miR-145; however, future studies are required to identify these factors.

The present study failed to perform the knockdown of miR-145 due to a technical problem. This experiment needs to be performed in future studies to further validate the conclusions of the present study. More cell lines also need to be used to analyze the effects of different expression levels of lncRNA GAS5 on cancer cell behaviors.

In conclusion, miR-145 and lncRNA GAS5 may function as tumor suppressors in prostate carcinoma. miR-145 may inhibit cell proliferation and induce apoptosis in human prostate carcinoma by upregulating lncRNA GAS5.

\section{Acknowledgements}

Not applicable.

\section{Funding}

The present study was funded by The Shanghai Municipal Commission of Health and Family Planning (grant no. 201540081).

\section{Availability of data and materials}

The analyzed datasets generated during the present study are available from the corresponding author on reasonable request.

\section{Author's contributions}

$\mathrm{XX}$ and WH designed experiments. XX, JD and $\mathrm{XH}$ performed experiments. $\mathrm{XX}, \mathrm{CF}$ and $\mathrm{WH}$ analyzed data. $\mathrm{WH}$ wrote the manuscript. All authors read and approved the final manuscript.

\section{Ethics approval and consent to participate}

The present study was approved by The Ethics Committee of Ruijin Hospital, Shanghai Jiaotong University (Shanghai,
China). All participants signed informed consent before admission.

\section{Patient consent for publication}

All patients signed informed consent for the possible publication of this study.

\section{Competing interests}

The authors declare that they have no competing interests.

\section{References}

1. Siegel RL, Miller KD and Jemal A: Cancer statistics, 2018. CA Cancer J Clin 68: 7-30, 2018.

2. Siegel RL, Miller KD and Jemal A: Cancer statistics, 2016. CA Cancer J Clin 66: 7-30, 2016.

3. Grasso CS, Wu YM, Robinson DR, Cao X, Dhanasekaran SM, Khan AP, Quist MJ, Jing X, Lonigro RJ, Brenner JC, et al: The mutational landscape of lethal castration-resistant prostate cancer. Nature 487: 239-243, 2012.

4. Gundem G, Van Loo P, Kremeyer B, Alexandrov LB, Tubio JMC, Papaemmanuil E, Brewer DS, Kallio HML, Högnäs G, Annala M, et al: The evolutionary history of lethal metastatic prostate cancer. Nature 520: 353-357, 2015.

5. Taft RJ, Pang KC, Mercer TR, Dinger M and Mattick JS: Non-coding RNAs: Regulators of disease. J Pathol 220: 126-139, 2010.

6. Esteller M: Non-coding RNAs in human disease. Nat Rev Genet 12: 861-874, 2011.

7. Mercer TR, Dinger ME and Mattick JS: Long non-coding RNAs: Insights into functions. Nat Rev Genet 10: 155-159, 2009.

8. Quinn JJ and Chang HY: Unique features of long non-coding RNA biogenesis and function. Nat Rev Genet 17: 47-62, 2016.

9. Gutschner T and Diederichs S: The hallmarks of cancer: A long non-coding RNA point of view. RNA Biol 9: 703-719, 2012

10. Gibb EA, Brown CJ and Lam WL: The functional role of long non-coding RNA in human carcinomas. Mol Cancer 10: 38, 2011.

11. Yu Y, Nangia-Makker P, Farhana L and Majumdar APN: A novel mechanism of lncRNA and miRNA interaction: CCAT2 regulates miR-145 expression by suppressing its maturation process in colon cancer cells. Mol Cancer 16: 155, 2017.

12. Zaman MS, Chen Y, Deng G, Shahryari V, Suh SO, Saini S, Majid S, Liu J, Khatri G, Tanaka Y and Dahiya R: The functional significance of microRNA-145 in prostate cancer. Br J Cancer 103: 256-264, 2010 .

13. Pickard MR, Mourtada-Maarabouni M and Williams GT: Long non-coding RNA GAS5 regulates apoptosis in prostate cancer cell lines. Biochim Biophys Acta 1832: 1613-1623, 2013.

14. Livak KJ and Schmittgen TD: Analysis of relative gene expression data using real-time quantitative PCR and the 2(-Delta Delta C(T)) method. Methods 25: 402-408, 2001

15. Braconi C, Kogure T, Valeri N, Huang N, Nuovo G, Costinean S, Negrini M, Miotto E, Croce CM and Patel T: MicroRNA-29 can regulate expression of the long non-coding RNA gene MEG3 in hepatocellular cancer. Oncogene 30: 4750-4756, 2011.

16. Ma MZ, Chu BF, Zhang Y, Weng MZ, Qin YY, Gong W and Quan ZW: Long non-coding RNA CCAT1 promotes gallbladder cancer development via negative modulation of miRNA-218-5p. Cell Death Dis 6: e1583, 2015.

17. Xue D, Zhou C, Lu H, Xu R, Xu X and He X: IncRNA GAS5 inhibits proliferation and progression of prostate cancer by targeting miR-103 through AKT/mTOR signaling pathway. Tumour Biol, 2016.

18. Pei J and Wang B: Notch-1 promotes breast cancer cells proliferation by regulating lncRNA GAS5. Int J Clin Exp Med 8: 14464-14471, 2015.

19. Du Y, Li J, Xu T, Zhou DD, Zhang L and Wang X: MicroRNA-145 induces apoptosis of glioma cells by targeting BNIP3 and Notch signaling. Oncotarget 8: 61510-61527, 2017.

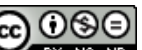

This work is licensed under a Creative Commons Attribution-NonCommercial-NoDerivatives 4.0 International (CC BY-NC-ND 4.0) License. 